\title{
Paulo Leminski, o poeta do labirinto
}

Arlindo Rebechi Junior

Docente do Departamento de Ciências Humanas da Faculdade de Arquitetura, Artes e Comunicação (FAAC) da Universidade Estadual Paulista (Unesp), atuando em diversos cursos na graduação e no Programa de Pós-Graduação em Comunicação. Doutor em Literatura Brasileira pela Faculdade de Filosofia, Letras e Ciências Humanas (FFLCH) da Universidade de São Paulo (USP).

E-mail: arlindo@faac.unesp.br

\section{LEMINSKI, ENTRE O "RIMBAUD CURITIBANO" E O "SAMURAI MALANDRO"1}

Na apresentação à obra de Paulo Leminski, Toda Poesia, de 2013, sua companheira e também poeta Alice Ruiz define a reunião ali exposta com uma precisão ímpar: "este livro é antes de tudo uma vida inteira de poesia" ${ }^{2}$. De alguma forma, Ruiz, ao definir a obra, delineava o que fora a vida do poeta. Nascido em Curitiba, em 1944, Leminski teve, desde jovem, uma vida inteira dedicada ao fazer poético: ao seu próprio fazer, pela produção de grande intensidade e originalidade na forma de poemas e na forma do romance; ao fazer de outros poetas, seja pela análise crítica entusiasmada e ensaística singular, seja como tradutor de inúmeras línguas, quando pôde introduzir legados poéticos importantes de diferentes partes do mundo.

O início da trajetória de Leminski como poeta está marcado pelo encontro com os poetas concretos. Seus poemas ganham as primeiras aparições na famosa revista Invenções, em 1964. Em uma entrevista dada a Regis Bonvicino, Leminski registra a importância do contato com o Concretismo e suas figuras-chave:

Minhas ligações com o movimento concreto são as mais freudianas que se possa imaginar.

Eu tinha 17 anos quando entrei em contato com Augusto, Décio e Haroldo.

O bonde já estava andando. A cisão entre concretos e neoconcretos cariocas já tinha acontecido. Olhei e disse: são esses os caras. Nunca me decepcionei. Neste país de pangarés tentando correr na primeira raia, até hoje eles dão de dez a zero em qualquer desses times de várzea que se formam por aí.

Só que descobri depois que há uma verdade e uma força nos times de várzea, nessa várzea subdesenvolvida, que eu quero.

A qualidade e o nível da produção dos concretos é um momento de luz total na cultura brasileira, como diz Risério. Mas eles não sabem tudo.

1. As expressões entre aspas são, respectivamente, de autoria de Haroldo de Campos e Leyla Perrone-Moisés. CAMPOS, Haroldo de. Paulo Leminski. In: LEMINSKI, Paulo. Caprichos \& relaxos. São Paulo: Brasiliense, 1983, p. 7.; PERRONE-MOISÉS, Leyla. Leminski, o samurai malandro. O Estado de S. Paulo, São Paulo, 27 nov. 1983. Caderno Cultura, p. 176.

2. RUIZ, Alice. Apresentação. In: LEMINSKI, Paulo. Toda poesia. São Paulo: Companhia das Letras, 2013, p. 7. 
A coisa concreta está de tal forma incorporada à minha sensibilidade que costumo dizer que sou mais concreto que eles: eles não começaram concretos, eu comecei ${ }^{3}$.

Olhando em retrospecto, é possível notar que Leminski, ainda que tenha tido grande identificação inicial com o grupo de poetas concretos, sua trajetória mostrou-se com corpo próprio. Se em diferentes momentos sua poesia deixava-se resvalar pela dicção concretista, em outros momentos, feita de um jogo complexo e sem regras pré-definidas, tornava-se a vazão de outros diálogos, em um amplo arco que vinha da poesia clássica grega à poesia de haicai japonesa, dando corpo a uma poesia de molde bastante experimental nos anos 1970.

Mas qual seria o papel ocupado pelo poeta curitibano na tradição literária brasileira? Situemos, primeiramente, o recorte temporal dessa poesia. Seu núcleo de poesia, por assim dizer, mais sólido, foi quase todo produzido entre os anos 1970 e 1980 e, como se deve prever, trata-se de uma poesia que também esteve embebida por uma atmosfera de mudanças, transformações, esperanças e desesperanças próprias daquele período.

Como todo bom poeta, que faz dialogar a experiência pessoal e a cultura de seu tempo, Leminski, por mérito próprio, conseguiu transformar pela sua poesia os limites entre polos estabelecidos: erudito e popular, filosofia e poesia, dissolvendo, em variados aspectos, os gêneros discursivos estabelecidos e realizando uma prática de escrita de caráter híbrido. O deslizamento de fronteiras talvez seja a marca mais original de sua inventividade poética. Cabe um trecho de Alfredo Bosi, extraído do seu já clássico História concisa da literatura brasileira, pela síntese que constrói sobre o poeta curitibano: "Leminski tentou criar não só uma escrita, mas uma antropologia poética pela qual a aposta no acaso e nas técnicas ultramodernas de comunicação não inibisse o apelo a uma utopia comunitária"4.

3. BONVICINO, Régis (org.). Envie meu dicionário: cartas e alguma crítica. 2. ed. São Paulo: Editora 34, 1999, pp. 208-209.

4. BOSI, Alfredo. História concisa da literatura brasileira. 43. ed. São Paulo: Cultrix, 2006, pp. 487-488.

\section{O POETA LABIRÍNTICO, NOS LIMITES DA FALA AUTOBIOGRÁFICA}

Uma boa definição para Leminski talvez seja a de um poeta labiríntico. Sem a necessidade de precisar o início do trajeto dessa sua poética e muito menos o fim de seu percurso, o seu leitor é convidado a participar de seus lances de dados: breves, menos breves, ora caprichosos, ora relaxados. Sua escrita nos leva a um passeio por diversas fontes, cujo resultado mais significativo é que, enquanto leitores, somos tragados para um jogo de decifrar cada um desses passos do processo poético instaurado pelo poeta.

Em livro, a estreia de Leminski se dá, em 1976, com a obra Quarenta clics em Curitiba. Publicado por uma editora bastante pequena, a Etecetera, a obra é uma espécie de fotolivro. Trata-se, na verdade, de uma combinação de quarenta fotos, em preto e branco, de autoria de Jack Pires e de quarenta poemas de Paulo Leminski, sendo todos eles dispostos em pranchas feitas em papel cartão. É curioso notar o modo como ocorreu o processo de seleção 
dos poemas presentes na obra. Alice Ruiz nos esclarece sobre isso: "em 1976, quando o fotógrafo Jack Pires chegou com a proposta de fazer um livro em conjunto com Paulo, espalhamos as fotos dele pelo chão e fomos procurando, entre os poemas curtos, quais conversavam ou rimavam com aquelas imagens".

A relação dos poemas com os registros de imagens da vida cotidiana de Curitiba - advindas de um certo acaso - fornecem ao leitor uma leitura de conjunto única. Os poemas se ressignificam pelas fotografias e estas se ressignificam pelos poemas, num processo, claramente, de interação entre dois sistemas semióticos. Veja-se o seguinte exemplo, retirado de uma dessas pranchas de Quarenta clics em Curitiba:

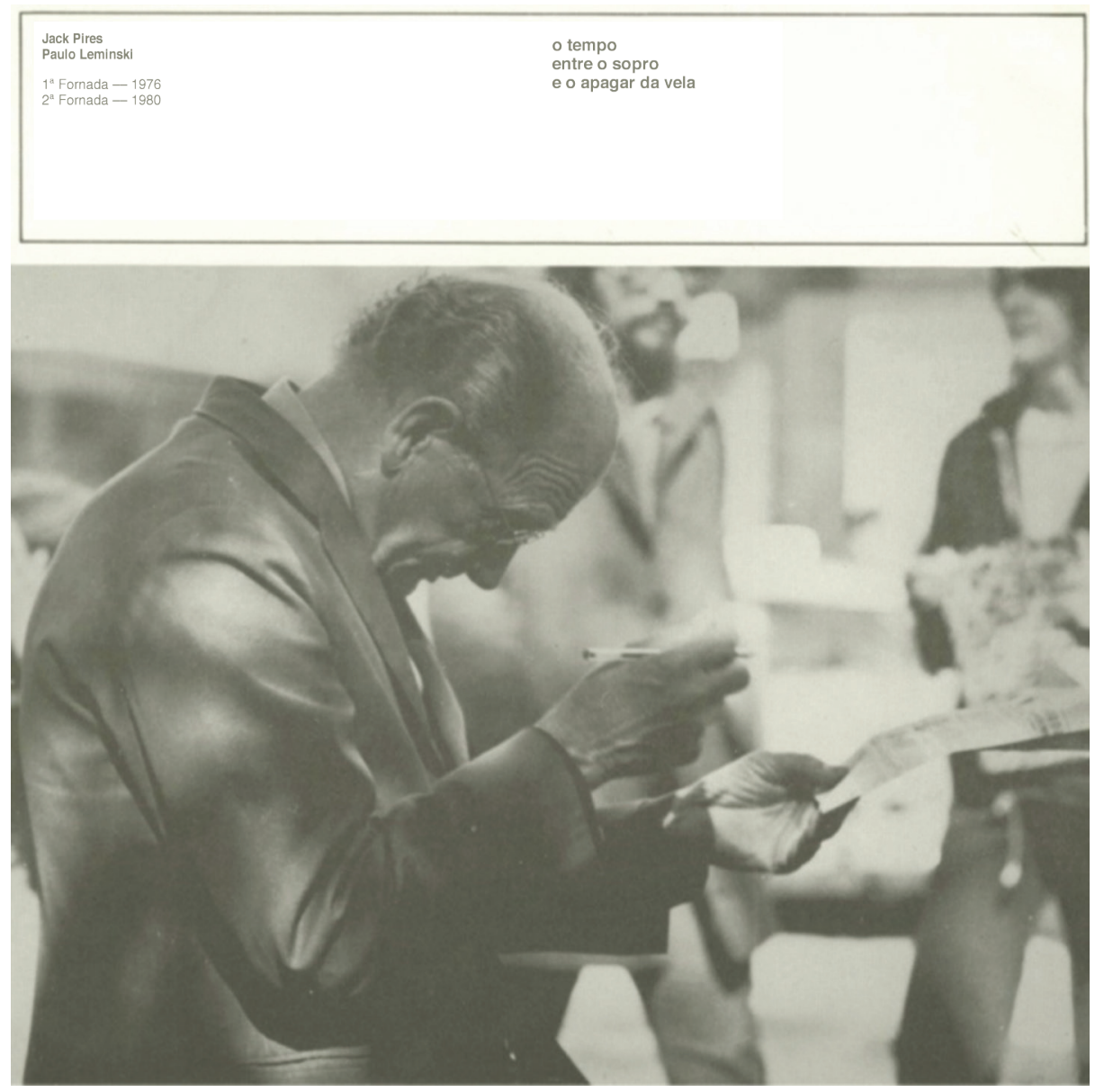

$\mathrm{Na}$ margem superior, um pouco mais à direita, temos o poema de Leminski (o tempo/ entre o sopro/ e o apagar da vela); mais abaixo, tomando parte significativa da página, encontra-se o instantâneo fotográfico de Jack Pires: uma imagem com dois planos, com o primeiro plano composto por um senhor que segura um pedaço de papel na mão de teor desconhecido e uma caneta, dando a dimensão de que possa haver ou ter havido algum tipo de intervenção por parte deste personagem; num segundo plano, com nítido desfoque, encontram-se duas pessoas, supostamente em movimento, em direção

5. RUIZ, Alice, op. cit., p. 8 . 
a se cruzarem. O contraste entre os planos é nítido: entre a forma estática do primeiro plano e aquilo que é movimento do segundo plano, o que cria para a fotografia uma forma representativa da própria duração do tempo, de um breve intervalo de tempo. Forma representativa esta que também está revelada no curto e denso poema de Leminski: entre o desejo do sopro e a vela que se apaga há também a marca da duração do tempo. Vai ser nesse entremeio que o tempo se estabelece por seus mínimos instantes. É nele que o poeta consegue reter do mínimo o máximo na sua imagem poética duradoura. Em termos intermidiáticos, a relação que se estabelece entre a fotografia e o poema de Leminski é a própria demarcação de uma forte exigência que o tempo impõe ao sistema de significação da fotografia, como forma de representação sempre de um instante do passado, e ao sistema de significação da poesia, cujo tempo é marca indelével do poeta e sua prática.

Tal como já havia ocorrido com Catatau, de 1975, seu romance e primeiro livro, e com Quarenta clics em Curitiba, as edições independentes eram, naquele momento, o modo que Leminski encontrava para divulgar os seus poemas. Em 1980, com a iniciativa de amigos, o poeta curitibano publica Não foi isso e era menos não fosse tanto e era quase. Seu terceiro livro, intitulado Polonaises, também saiu nesse mesmo ano em edição também independente. Serão esses dois livros que, junto com outros poemas inéditos do poeta, formarão a obra Caprichos E relaxos, lançado em 1983, pela editora Brasiliense e por iniciativa do editor Luiz Schwarcz.

Caprichos Ẽ relaxos possui sete seções. Como já dito, além das duas seções resultantes dos dois livros de poemas anteriores publicados de maneira independente, Leminski reedita na obra os poemas publicados na revista Invenções, nos anos 1960, e quase a totalidade dos seus poemas inéditos até aquele momento. Talvez a unidade presente em Caprichos Ẽ relaxos se estabeleça pelas vozes heterogêneas que ali rodeiam o fazer poético, legando ao próprio leitor a forma de mediação exigida pelas diferentes formas exploradas nos poemas. Confere-se ao leitor a tarefa de lidar com esse labirinto textual, é o que alerta o poeta logo no início do volume aos seus leitores:

Aqui, poemas para lerem, em silêncio,

o olho, o coração e a inteligência.

Poemas para dizer, em voz alta.

Poemas, letras, lyrics, para cantar.

Quais, quais, é com você, parceiro. ${ }^{6}$

É nítido, em Caprichos Ẽ relaxos, o trabalho da fala autobiográfica do poeta, em que pese a liberdade, com uma certa dose de acaso, e suas formas poéticas que deformam, em certo sentido, o próprio real. Em diferentes poemas, estão elencados o desejo, a memória e a demarcação do próprio poeta na tradição

6. LEMINSKI, Paulo. Toda poesia. São Paulo: Companhia das Letras, 2013, p. 27. poética, que sempre está disposto a refletir sobre o seu próprio fazer poético. É o caso do pequeno poema encontrado na seção de abertura do livro "caprichos \& relaxos (saques, piques, toques \& baques)": 
parar de escrever

bilhetes de felicitações

como se eu fosse camões

e as ilíadas dos meus dias

fossem lusíadas,

rosas, vieiras, sermões ${ }^{7}$

Mais à frente, na seção "não fosse isso e era menos não fosse tanto e era quase", de Caprichos Ẽ relaxos, um outro poema chama a atenção pela sua forma concisa e objetiva de uma dicção que mescla, notadamente, o humor e a própria forma da fala autobiográfica:

O pauloleminski

é um cachorro louco

que deve ser morto

a pau e pedra

a fogo a pique

senão é bem capaz

o filhadaputa

de fazer chover

em nosso piquenique. ${ }^{8}$

No núcleo do poema está o próprio poeta, que transformado está em substantivo comum. Daquilo que seria o clichê do poeta como um louco, Leminski consegue extrair o que há de mais cômico no poema. A sonoridade, formulada por muitos pentassílabos, dá ao poema o ritmo ágil em dicção coloquial, em que se contrapõe uma ideia central: o poeta, que aqui é "cachorro louco" e o "filhadaputa", está em contraposição ao conservadorismo presente em outro polo social, talvez o da família tradicional e suas formas de diversão. O poeta, nesse caso, representaria o próprio elemento de desestabilidade; torna-se maldito. Esse mesmo horizonte de sua fala autobiográfica e reflexiva estaria em um outro poema desta mesma seção "não fosse isso e era menos não fosse tanto e era quase":

eu queria tanto ser um poeta maldito a massa sofrendo enquanto eu profundo medito

eu queria tanto ser um poeta social rosto queimado pelo hálito das multidões

em vez olha eu aqui pondo sal nesta sopa rala que mal vai dar para dois ${ }^{9}$

7. Ibidem, p. 41.

8. Ibidem, p. 102

9. Ibidem, p. 90. 
Aqui, todavia, o dado reflexivo é no sentido de situar a própria ordem de preocupação estética do poeta. Mais uma vez, a fala autobiográfica sobressai. Talvez se possa dividir o poema em três partes: a primeira estrofe representaria a matriz da poesia dita maldita, a dos poètes maudits, em alusão ao termo difundido pelo poeta francês Paul Verlaine para se referir a poetas como Stéphane Mallarmé e Arthur Rimbaud, que, por suas preocupações formais, morais e existenciais, propositadamente eram deixados de lado pela crítica de então; a segunda estrofe, em contraposição à primeira matriz, seria legítima para pensar a tradição de cunho social de romancistas e poetas desde os românticos; a terceira estrofe, por sua vez, abre flanco para um caminho do poeta mais pessoal e íntimo que contrapõe os outros dois percursos antes enunciados. Está nessa terceira estrofe a própria tônica de uma geração de poetas dos anos 1970, cujo propósito enunciativo estaria muito mais fincado naquilo que seriam suas memórias e desejos privados e cotidianos. O poeta aqui se preocupa não mais com as grandes discussões, sejam elas as grandes vertentes estéticas ou as grandes vertentes da poesia social, mas sim com as condições do seu próprio fazer poético em uma sociedade pós-industrial. Aqui, para o poeta, tudo se torna frágil e sua sopa pode mal alimentar dois. Com a última estrofe, o poema se atualiza com seu próprio tempo e adquire uma atmosfera melancólica própria da precariedade vivida pelo poeta.

Nesse sentido, o poeta e crítico Régis Bonvicino faz uma síntese bastante justa para a poesia levada a cabo por Leminski. Cabe conferir:

A concisão, na poesia de Leminski, surge como um dado de linguagem objetiva e possibilidade de registro subjetivo, na contramão do lirismo prolixo, à brasileira. Se Oswald foi o inventor do poema-minuto, arriscaria dizer que Leminski criou alguma coisa como o poema instantâneo, fundindo a infraestrutura concretista com a dicção coloquial e anárquica inventada aqui por Caetano Veloso e Torquato Neto. A estes dois elementos acrescentou o dado biográfico - não como confissão, mas como escárnio ou reparação ${ }^{10}$.

Na seção "polonaises", de Caprichos Eं relaxos, Leminski aponta para mais uma reflexão a partir da sua própria experiência como poeta. Diz ele:

um dia

a gente ia ser homero

a obra nada menos que uma ilíada

10. BONVICINO, Régis. A antilírica concisa do poeta Paulo Leminski. Folha de S. Paulo, São Paulo, 21 ago. 1994. Caderno Mais!, p. 10

11. LEMINSKI, Paulo, op. cit., p. 71.

depois

a barra pesando

dava pra ser aí um rimbaud

um ungaretti um fernando pessoa qualquer

um lorca um éluard um ginsberg

por fim

acabamos o pequeno poeta de província

que sempre fomos

por trás de tantas máscaras

que o tempo tratou como a flores ${ }^{11}$ 
Numa clara demonstração de que o poema pertence ao seu tempo, próprio de uma poesia marginal, perpassam pelo seu tecido textual os versos livres e sem pontuação, os nomes próprios que se transformam em substantivos simples e um certo coloquialismo que redimensiona o poeta no seu espaço cotidiano. Tal como um texto de balanço sobre uma experiência vivida, o poema segue como objeto a temporalidade da vida trazida pelo poeta. No início de cada uma das estrofes instituem-se as marcas adverbiais: "um dia", "depois" e "por fim”. A enunciação trazida pelo poema evoca três temporalidades distintas - da epopeia grega, da modernidade poética instituída e do mundo contemporâneo de vivência do poeta. Todas estas temporalidades dizem muito sobre o eu lírico que fala no poema: de Homero, representante máximo da poesia clássica, vem o símbolo de um tempo passado, cheio de expectativas e desejos da obra máxima; em direção à modernidade, Rimbaud, Ungaretti, Lorca, entre outros, são aquilo que, com lances já de melancolia enunciados (“a barra pesando"), representavam a distância a um tipo de poesia não mais alcançável; restava, melancolicamente, ao poeta ser ele mesmo o legítimo representante da província. Era o que lhe restava. Com a ausência do humor, muito presente em seus outros poemas, dá vazão, neste experimento verbal, ao espaço da crise e da melancolia.

\section{A PONTE BRASIL-JAPÃO}

Em 1987, Leminski publica o seu último livro em vida, cujo título é Distraídos venceremos. A obra, de certa maneira, é um espaço de continuidade das reflexões de sua obra anterior, Caprichos Ẽ relaxos, com um adendo enunciado pelo poeta no texto introdutório da edição: "arrisco crer ter atingido um horizonte longamente almejado: a abolição (não da realidade, evidentemente) da referência, através da rarefação"12.

Bastante representativo desse período do poeta é o poema "Aço em flor", que é dedicado a "Koji Sakaguchi, portal amigo entre o Japão e o Brasil":

Quem nunca viu

que a flor, a faca e a fera

tanto fez como tanto faz,

e a forte flor que a faca faz

na fraca carne,

um pouco menos, um pouco mais, quem nunca viu

a ternura que vai

no fio da lâmina samurai,

esse, nunca vai ser capaz. ${ }^{13}$

"Aço em flor" é um poema de singular sonoridade, resultante em parte pelas muitas aliterações advindas dos fonemas /f/ e / k/ e em parte pelas rimas, ora assonantes e ora aliterantes dispostas ao longo do poema. De nada, todavia, valeriam os sons, se não pudéssemos extrair os sentidos. Conforme

12. LEMINSKI, Paulo.
Transmatéria contras-
senso. In:
poesia. São Paulo: Com-
panhia das Letras, 2013 ,
p. 404.
13. LEMINSKI, Paulo, op.
cit., p. 198. 
nos esclarece o velho mestre Antonio Candido, "este é o problema da expressividade dos sons, da correspondência entre som e um sentido necessário, cuja forma mais complexa é a sinestesia, ou simultaneidade de sensações"14. Se a sonoridade do poema sugere um caminho expressivo a percorrer, os signos verbais suscitados e suas imagens se impõem, ao leitor, por variada mediação, em sentidos alinhados à experiência do poeta e o seu mundo de interesse ao redor.

Para chegar, potencialmente, aos vários significados que são modulados pelo poema, é interessante notar o papel desempenhado pela própria cultura japonesa para o poeta curitibano. Praticante da arte do judô, biógrafo de Bashô e tradutor de Yukio Mishima, Leminski mostrou-se, ao longo de toda a sua trajetória, muito interessado pelas coisas do Japão. As imagens que se formam em "Aço em flor" evocam, de algum modo, esse seu empenho e compromisso. Ainda que no poema possam se sustentar certas imprecisões típicas de um intencional coloquialismo ("quem nunca viu", "tanto fez como tanto faz", "um pouco menos, um pouco mais"), as imagens evocadas pelo trabalho lexical/sonoro com "flor" e "faca" são de grande precisão, beirando o rigor de síntese das imagens de haicais. Do sétimo ao último verso, que se configuraria como uma espécie de segunda parte do poema, a precisão da imagem, da lâmina que adentra a carne ("a ternura que vai/ no fio da lâmina samurai”), encanta pelo seu tom a um só tempo melancólico e belo. Sua imagem-síntese, em alusão às cerimônias rituais japonesas de Seppuku, em que o guerreiro samurai praticava o suicídio cortando o próprio ventre, parece superar a utilidade imediata do objeto, realocando-o sob outros sentidos nunca antes explorados.

Sem dúvida, Distraídos venceremos é um livro que demonstra com grande ímpeto o diálogo de Leminski com a cultura japonesa. Umas das seções do livro, denominada "kawa cauim desarranjos florais", faz alusão ao ideograma de kawa, que indica "rio" em japonês. Para tanto, Leminski dá o seguinte dado explicativo: "pictograma de um fluxo de água corrente, sempre me pareceu representar (na vertical) o esquema do haikai, o sangue dos três versos correndo na parede da página" ${ }^{15}$. Leminski, por toda a seção, explorará, a seu modo, a forma japonesa do haicai. Indubitavelmente, Leminski é um dos que melhor aclimatou o gênero entre nós. O crítico Paulo Franchetti, ao historiar a forma do haicai no Brasil, registra a importância do poeta dentro da cultura brasileira:

14. CANDIDO, Antonio. O estudo analítico do poema. 3. ed. São Paulo: Humanitas, 2004, p. 38.

15. LEMINSKI, Paulo, op. cit., p. 233.

16. FRANCHETTI, Paulo. O haicai no Brasil. Alea, Rio de Janeiro, v. 10, $\mathrm{n}$ 2, jul./dez. 2008, p. 265.
A importância de Leminski, na história da apropriação do haicai pela cultura brasileira é grande, porque nele se vai juntar a abordagem tecnicista da poesia concreta com o orientalismo zenista que marcou a contracultura na segunda metade do século XX. Com propriedade, Caetano Veloso o definiu como "clima/ mistura de concretismo com beatnik" e nele viu um "haicai da formação cultural brasileira"16.

Desta seção de Distraídos venceremos, pode-se extrair o seguinte poema: 


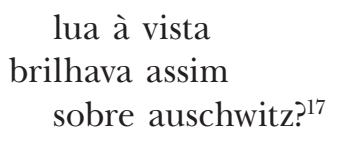

Aproveitando o trabalho com uma mesma figura, a lua, coloco em paralelo um outro exemplo. Da seção "Ideolágrimas", em Caprichos Ẽ relaxos, vem um outro poema identificado com a forma do haicai:

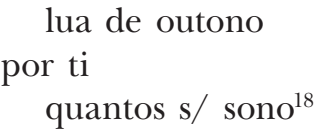

Em ambos os poemas o tema explorado é a lua. Mas há diferenças na abordagem em um e outro caso. Como se sabe, a lua é um objeto presente em muitos haicais. Este segundo poema de Leminski, por exemplo, é a própria releitura de um celebrado poema de Bashô sobre a contemplação da beleza da lua cheia. O poema segue os preceitos que resultam no caminho do haicai: (1) a observação à lua que se impõe no céu é motor para a realização poética; (2) o poema é resultante de uma rápida anotação, longe do virtuosismo e próximo de um impulso do próprio poeta.

Já no primeiro poema a representação da lua se distancia desse dado objetivo da observação direta do objeto, seguida da anotação rápida. A chave de leitura desse poema está em seu último verso (“sobre auschwitz?”): seu efeito é reflexivo e traz um olhar atento e crítico sobre a tragédia histórica dos campos de concentração. De acordo com a estética preconizada por Bashô, é possível tratar esse poema como um haicai? É sabido que ter um terceto de versos livres não é apenas o que se exige para que a forma do haicai se estabeleça. Talvez a melhor maneira de encararmos esse primeiro poema, e aceitá-lo como um haicai, seja compreendê-lo sob a forma inclusiva que um tipo de poesia pode postular diante dos objetos do mundo. De Bashô, é conhecida a forma generosa e solidária como encara o poema do discípulo e o transforma pelo modo inclusivo: seu aluno teria realizado o seguinte haicai: "uma libélula/ tirando-lhe as asas/ uma pimenta" e Bashô, sabiamente, o modifica: "uma pimenta/ colocando-lhe asas/ uma libélula". O haicai seguiria, nesse horizonte inaugurado por Bashô, como uma poética da inclusão e da solidariedade. Para Leminski, neste primeiro poema, a reflexão sobre o que ocorrera em Auschwitz representaria uma forma de inclusão na dor do outro e um grito solidário ao que de mais grave ocorrera no passado.

Notem-se alguns tercetos presentes em diferentes etapas de sua trajetória, muitos deles identificados como haicais:

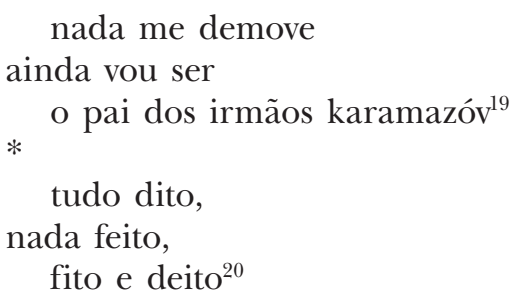

17. LEMINSKI, Paulo, op.

cit., p. 240.

18. Ibidem, p. 117.

19. Ibidem, p. 116.

20. Ibidem, p. 240 


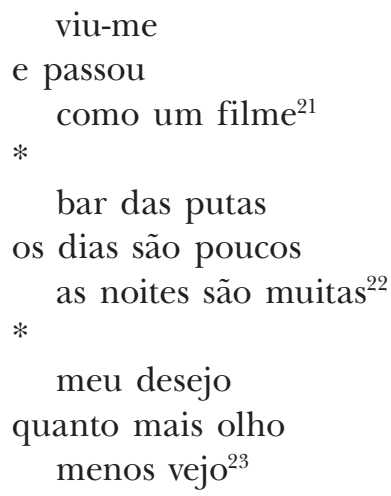

Ainda em que pese todo o seu apreço e interesse pela forma literária, por excelência, dos japoneses e a vocação do poeta curitibano em disseminar de forma massiva e midiática os propósitos dessa forma do haicai, há na poesia de Leminski, a mais identificada com esse gênero japonês, um tipo de aclimatação muito própria, que, em variados momentos, dá vazão a torneios verbais e efeitos muito bem arquitetados, como demonstra os exemplos previamente elencados. Se alguns leitores o uso desses artifícios sonoros e expressivos significaria o afastamento do que, filosoficamente, representaria o próprio haicai - um tipo de afastamento dessa espontaneidade almejada e de uma certa incompletude que a forma clássica de um haicai sugeriria -, na visão de outros leitores isso pode representar o alcance da tão desejada comunicação com o público. E nesse quesito, seguindo as trilhas dos tropicalistas, Leminski foi mestre, talvez mais que os outros poetas de sua geração. Não à toa, Caetano Veloso, além de achá-lo um sujeito gozado, o achava um tremendo barato.

\section{REFERÊNCIAS BIBLIOGRÁFICAS}

BONVICINO, Régis. A antilírica concisa do poeta Paulo Leminski. Folha de S. Paulo, São Paulo, 21 ago. 1994. Caderno Mais!, p. 10.

. (org.) . Envie meu dicionário: cartas e alguma crítica. 2. ed. São Paulo: Editora 34, 1999.

BOSI, Alfredo. História concisa da literatura brasileira. 43. ed. São Paulo: Cultrix, 2006.

CAMPOS, Haroldo de. Paulo Leminski. In: LEMINSKI, Paulo. Caprichos \& relaxos. São Paulo: Brasiliense, 1983, p. 7.

CANDIDO, Antonio. O estudo analítico do poema. 3. ed. São Paulo: Humanitas, 2004.

FRANCHETTI, Paulo. O haicai no Brasil. Alea, Rio de Janeiro, v. 10, n. 2, pp. 
Paulo Leminski, o poeta do labirinto - Arlindo Rebechi Junior

LEMINSKI, Paulo. Toda poesia. São Paulo: Companhia das Letras, 2013.

PERRONE-MOISÉS, Leyla. Leminski, o samurai malandro. O Estado de S.

Paulo, São Paulo, 27 nov. 1983. Caderno Cultura, p. 176.

RUIZ, Alice. Apresentação. In: LEMINSKI, Paulo. Toda poesia. São Paulo:

Companhia das Letras, 2013. pp. 7-8. 